\title{
Atmospheric stability affects wind turbine power in large offshore wind farms
}

\author{
Peng Xiufang ${ }^{1, ~ a, ~} \mathrm{Hu}_{\mathrm{Yu}}^{1, \mathrm{~b}}$, Xiang Wen ${ }^{1, \mathrm{c}}, \mathrm{Xu} \mathrm{Cang}^{2, \mathrm{~d}}$, Xue Feifei ${ }^{2, \mathrm{e}}$ \\ ${ }^{1}$ Jiangsu Province Electric Power Design Institute, Nanjing, 211102, China \\ ${ }^{2}$ The College of Energy and Electrical Engineering, Hohai University, Nanjing, 211100, China

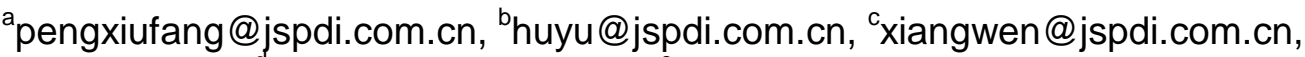

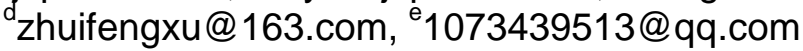

Keywords: offshore wind farm; atmospheric stability; sea surface roughness; Richardson gradient method; output power

Abstract. With the rapid development of offshore wind power industry, it is significant to improve the accuracy of offshore wind energy assessment. Sea surface roughness and atmospheric thermal stability are main factors that influence the offshore wind energy. But at present, most researches on micro-scale aerodynamic field of wind farms are based on neutral atmospheric condition, few takes thermal stability into account; also, sea surface roughness is often set as a constant, which reduces the accuracy of offshore wind energy assessment. This paper researches the thermal stability of an offshore wind farm in Jiangsu Province, gives a suitable way to decide thermal stability for offshore wind farms. Also, it analyzes variation of output power of the turbines in a column under different thermal conditions, with roughness into account, to consider their impact on offshore wind farms. The result shows that when roughness is big enough, thermal stability has little influence on output power; while sea surface roughness is small enough, thermal stability has a dominant influence on output power.

\section{Introduction}

With the further development of wind energy resources, wind farm construction has been gradually moved to complex terrain and offshore areas ${ }^{[1]}$. Wind resources are rich in eastern coastal areas. Compared with the wind in onshore wind farms, offshore wind speed is higher and out of environmental constraints. At the same time, most offshore wind farms are close to the electricity load center and have a good condition of electricity interconnection, and they are easy to be developed in large scales, so we can judge that offshore wind farms have a bright future. The China National Energy Administration has made a plan of offshore wind power development in the $13^{\text {th }}$ Five-year Plan and the installed capacity is aimed at 10 million $\mathrm{kW}^{[2]}$. Offshore wind power will be in a period of rapid development.

The development of offshore wind power in China is still in its infancy, and accurate assessment of the offshore wind resources is in an urgent need among the development of offshore wind power. Thermal stability has an important impact on offshore wind resources, but the study of offshore wind farms in the atmosphere is often assumed to be neutral. That means thermal stability hasn't been taken into consideration. For lower average wind speed $\left(<6 \mathrm{~m} \cdot \mathrm{s}^{-1}\right)$ wind farm, the impact of thermal effects on the atmosphere become very important ${ }^{[3]}$. Studies on offshore wind farms were started earlier in foreign countries than that in China, so the studies of aerodynamics in offshore wind farms are much fewer and most of them are concentrated on numerical simulation of wind resource in mesoscales, research of three dimensional sea breeze, etc. There hasn't been further study on the effects of atmospheric thermal stability for offshore wind farms.

Alfredo Peña ${ }^{[4,5]}$ analyzed the data of wind turbines' power loss in Horns Rev based on different thermal stability conditions and described the wind contour in this region. They analyzed output power of a row of wind turbines which are lined from east to west and came to a conclusion that power loss under the stable condition is much less than that under unstable condition, which is almost the same as the simulation results of the improved Jensen Wake Model. Monin-Obukhov Similarity 
Theory was applied to analyzing data on wind speed by Andrea Venora ${ }^{[6]}$ and studied factors such as sea surface, temperature, distance from shore, reference wind speed, etc. Blackadar ${ }^{[7]}$ and Lettau ${ }^{[8]}$ proposed a wind shear model which can be extended to the entire height of the boundary layer in neutral state. Peña ${ }^{[9]}$ applied Rossby number similarity theory ${ }^{[10]}$ and extended the model to all thermal stability conditions. Gryning ${ }^{[11]}$ applied Rossby number similarity theory and established a new model of wind contour which took thermal stability into consideration and was applicable to the entire height of the atmospheric boundary layer.

Nikola $^{[12]}$ analyzed operating data to study the influence of thermal stability to the output and came out that thermal stability had a great influence on wind speed assessment at hub height. Also, they made a conclusion that wind shear exponent is much smaller under unstable conditions than that under stable conditions. Sonia and Julie ${ }^{[13]}$ studied operating data and found out that thermal stability, wind shear and turbulence would affect the actual wind turbine power output. They also found that output power in stable conditions was larger than in unstable conditions obviously in the condition of the same wind speed. Mandar Tabib ${ }^{[14]}$ simulated the flow field of offshore wind farm by actuator line model, which based on the atmospheric stability and the influence of topography, results shows the importance of the atmospheric stability and the reduction of the scale to improve the accuracy of calculation.

It is commonly agreed that whether the wind farms can be constructed successfully or not mainly depends on the assessment of wind resource. There is a huge difference in wind resource under different thermal stability conditions, which have a great influence on offshore wind farms.

\section{Calculation method of atmospheric stability}

Atmospheric thermal stability refers to the degree of suppression or strengthening of vertical motion is affected by the temperature distribution of the atmosphere. Common thermal stability calculation methods include the P-T method, radiation method and wind direction standard deviation $\left(\sigma_{\theta}\right)$ method, $\Delta T$ method, $\Delta T / U$ method, wind speed ratio method $\left(U_{R}\right)$; when considering the dynamic of atmospheric turbulence and thermal characteristics, there are Monin-Obukhov length method $(L)$, Richardson bulk method $\left(R i_{b u l k}\right)$, Richardson gradient method $\left(R_{i}\right)$ and the profile method. Profile method can be divided into three methods: Sea Temperature Profile Method $\left(T_{\text {sea }}\right)$, temperature difference profile method $\left(T_{\text {diff }}\right)$, wind speed and temperature difference profile method $\left(U_{\text {diff }} T_{\text {diff }}\right)$. Domestic recommend thermal stability rating is revised Pasqual Classification $(\mathrm{P} \cdot \mathrm{S})$, which is divided into six levels: strongly unstable, unstable, weakly unstable, neutral, relatively stable and very stable, denoted as A, B, C, D, E, F. Foreign division of thermal stability contains level G, which can be classified as F class.

For Richardson gradient method, $R_{i}$ can be calculated as:

$$
\begin{aligned}
& R_{i}=\frac{g \times Z}{T_{10}} \times \frac{\Delta T}{\Delta u^{2}} \times \ln \frac{z_{2}}{z_{1}} \\
& \mathrm{Z}=\sqrt{z_{1} \times z_{2}}
\end{aligned}
$$

Where $z_{1}$ and $z_{2}$ are two different height levels, $T$ is the average temperature of two levels, $\Delta T$ is the temperature difference between two levels, $\Delta u$ is velocity difference between two levels. The classification of Richardson numbers are shown in Table. 1.

Table.1 Classification based on the number of Richardson

\begin{tabular}{lccccccc}
\hline Level & $\mathrm{A}$ & $\mathrm{B}$ & $\mathrm{C}$ & $\mathrm{D}$ & $\mathrm{E}$ & $\mathrm{F}$ & $\mathrm{G}$ \\
\hline$R_{i}$ & $R_{i} \leq-10$ & $-10<R_{i} \leq-2.5$ & $-2.5<R_{i} \leq-0.6$ & $-0.6<R_{i} \leq 0.2$ & $0.2<R_{i} \leq 1$ & $1<R_{i} \leq 3$ & $R_{i}>3$ \\
\hline
\end{tabular}




\section{Introduction of the offshore wind farm}

The offshore wind farm is located in the coastal of Jiangsu Province, distribution of wind turbine sites and met masts are shown in Figure 1. Each row of wind turbine is arranged in the direction of $22^{\circ}, \mathrm{M}_{1}$ is an offshore met mast, $\mathrm{M}_{2}$ is a met mast on the coastal embankments and the distance between them is $21 \mathrm{~km}$. In the research, wind farm's operational data and measured data are in the same period, data sample interval time is $10 \mathrm{~min}$. Wind turbine models referred mainly in this paper is SWT 2.37-101, whose hub height is $80 \mathrm{~m}$.

Fig. 2 is the comparison of wind velocity in different heights of the same period between onshore met mast $\mathrm{M}_{2}$ and offshore met mast $\mathrm{M}_{1}$, the figure shows that the wind speed reach the peak at 15:00 at the height of $10,50,70,80 \mathrm{~m}$, which is related to solar radiation. 15:00 is the moment when solar radiation is strongest in a day, and the temperature in the land is much higher than that in the sea, the sea breeze effects results in the maximum wind speed at 15:00.

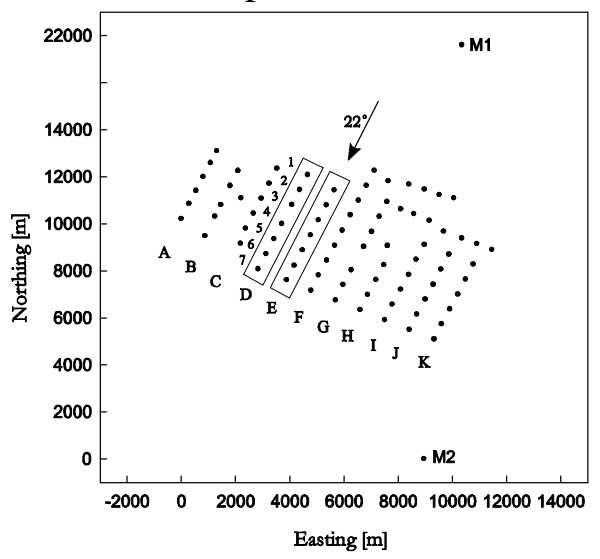

Fig. 1 Distribution of wind turbine and the location of the met mast

The peak of wind speed at $M_{1}$ is latter than $M_{2}$, the wind speed at $M_{2}$ increases rapidly after 6:00 at $10 \mathrm{~m}$, and decreases after 15:00 gradually, the same as other heights, the trend is more obvious, which indicates that surface temperature increases after 6:00, and results in the decrease of atmospheric thermal stability in the surface and the increase of turbulence vertically, so wind speed increase rapidly at $10 \mathrm{~m}$; the rule and variation magnitude of $\mathrm{M}_{2}$ 's wind speed are same at different heights. We can conclude from the comparison that in offshore wind farm's coastal regions, wind speed of lower layer varies greatly by the influence of the thermal stability.
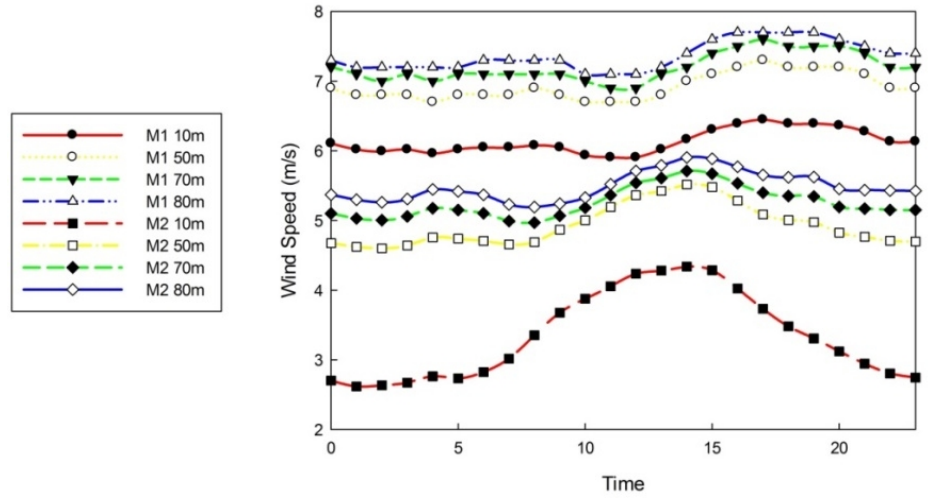

Fig. 2 Comparison of wind speed at different heights

\section{Calculation of atmospheric stability}

Due to large differences between heat capacity of sea and land, sea temperature changes slowly, the lower atmosphere of the sea may not be stable at night, while the P-T method directly classifies the night as stable state, apparently, it can't be applied to thermal stability determination of offshore wind farm. 
The frequency distribution histogram of the thermal stability is calculated by 5 ways in Figure 3 , we can see that different thermal stability determination methods differ greatly. A class is $59 \%$ with $\Delta T$ method, significantly higher than other methods; A class is $19 \%$ with $\Delta T / U$ method, B class is $35 \%$, frequency of unstable is a little higher; In wind direction standard deviation method, D class is $22 \%$, E class is $40 \%$, frequency distribution of all levels are reasonable; In $L$ method, C class is $61 \%$, significantly higher than other methods; In Richardson gradient method, $\mathrm{C}$ class is $37 \%$, D class is $31 \%$, frequency distribution of every level is also relatively reasonable.

We can conclude that Richardson gradient method and direction standard deviation method can be reasonable to divide thermal stability, due to the wind direction standard deviation method is a direct parameter characterizing the turbulence intensity, which is suitable for flat terrain; Richardson number combines the effect of the thermodynamic factor and dynamic factor, reflecting more information about turbulent, which can determine the thermal stability under different boundary conditions accurately. In the following study, we use gradient Richardson number method to determine the thermal stability.

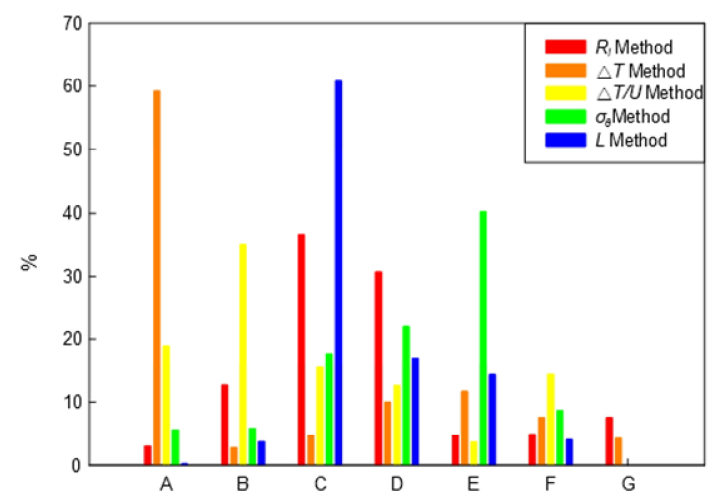

Fig. 3 Frequency histograms for each stability condition

The curve about daily variation of Richardson number at $\mathrm{M}_{2}$ is shown In Fig. 4. We can see annual average Richardson number is negative from 6:00 to 20:00, annual daily variation of average Richardson number is positive from 21:00 to 5:00. Richardson number is higher at night, which indicates in stable state, Richardson number is lower in the daytime, which indicates in unstable state. Daily variation of Richardson number changes a little in summer, while it changes a lot in winter, and the value of daily variation is similar in spring and autumn.

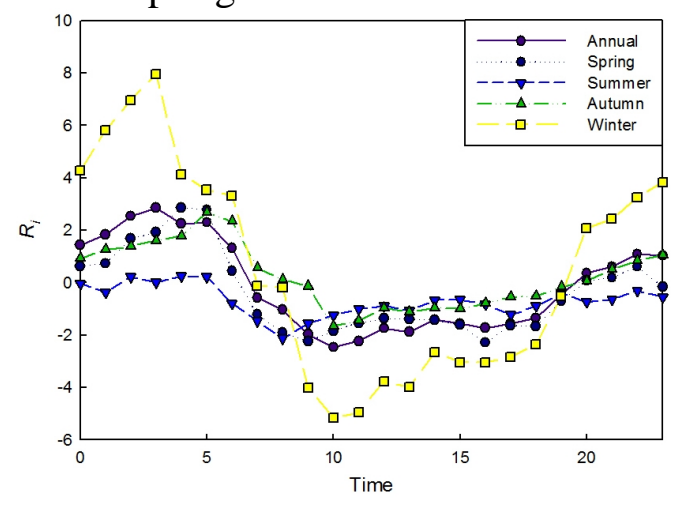

Fig. 4 Daily variation curve of Richardson number

\section{Analysis of the impact of thermal stability on output power}

In Fig.1, the depth of the sea water increases from the southwest corner to the northeast corner. There is a deep-water band between Column $\mathrm{D}$ and $\mathrm{E}$ with its direction of $202^{\circ}$, which starts from the 5th turbine and extends towards northeast. The water is deeper than that of both sides, and is often under water throughout the year. So for the turbines in Column D/E, when the wind direction is $22.5^{\circ}$, they have similar underlying surfaces and close sea surface roughness. However, when the wind direction is $7.5^{\circ}$, they have different underlying surfaces (the roughness of underlying surface in 
Column D is much bigger than that in Column E), which could then be used to research the impact of different roughness and thermal stability conditions on output power of turbines.

In this research, thermal stability conditions are divided into 4 types: Stable, which corresponds to thermal stability level E \& F; Neutral, corresponds to level D; Unstable, corresponds to level C; and finally Very Unstable, corresponds to level A \& B. Both $\mathrm{E}_{1}$ and $\mathrm{M}_{1}$ are met the condition with wind speed range between $4 \sim 11 \mathrm{~m} . \mathrm{s}^{-1}$ and wind direction range between $7.5 \pm 7.5^{\circ}$ and $22.5 \pm 7.5^{\circ}$. The thrust coefficient of a wind turbine doesn't vary much within the range between $4 \sim 11 \mathrm{~m}^{-1}{ }^{-1}$.

Fig.5 gives the wind attenuation curve and the output power attenuation curve at hub height under different thermal stability conditions. $U_{\text {free }}$ is the wind speed at hub height of the $1^{\text {st }}$ turbine in a column that doesn't affected by wake effects, and $P_{\text {free }}$ is the output power of that turbine; $U_{i}$ is the wind speed at hub height of the $\mathrm{i}^{\text {th }}$ turbine in a column, and $P_{i}$ is the output power of that turbine.
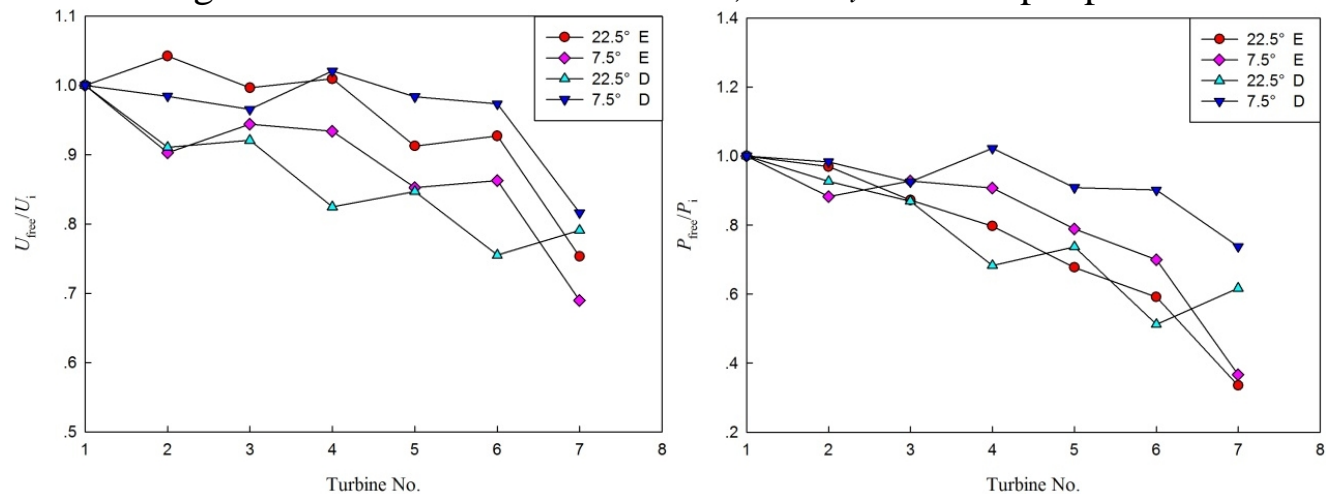

(a)Stable
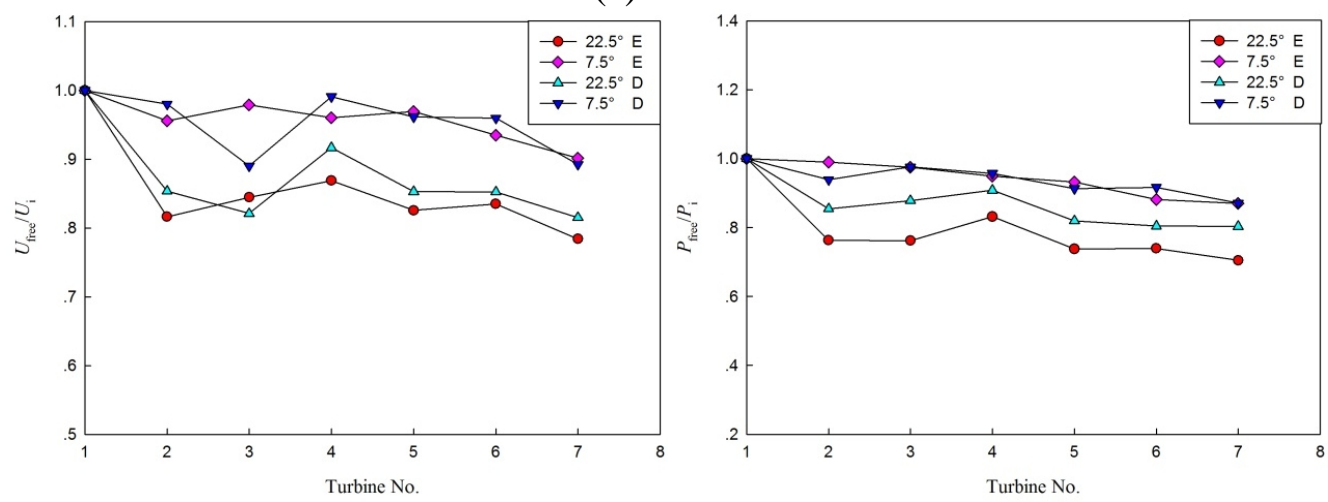

(b)Neutral
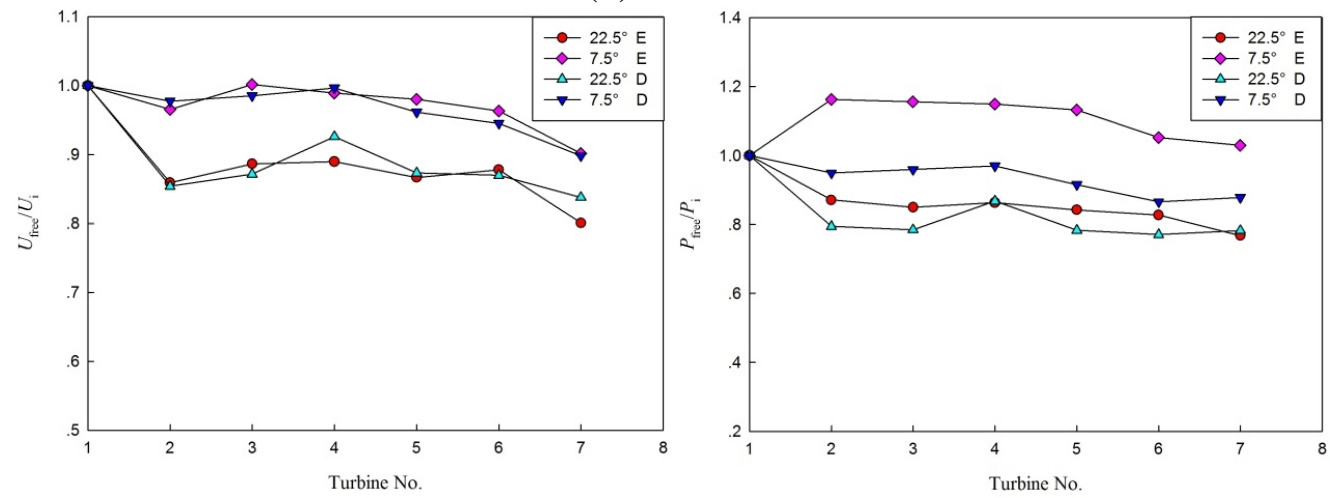

(c)Unstable 

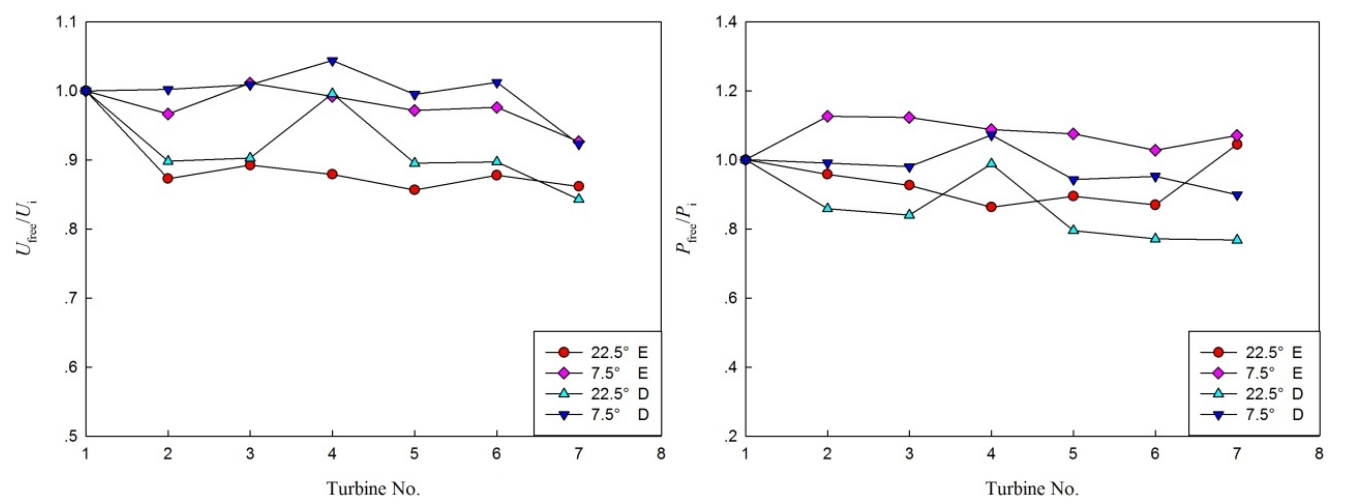

(d)Very Unstable

Fig. 5 Characteristic attenuation curve of wind speed (left) and power (right) in D/E column

By comparing these four output power curves in Fig.5, we can see that, under Stable condition, the output power decreases faster than that under Unstable condition, so wake decays faster under Stable condition. When wind direction is $7.5^{\circ}$, the incident wind speeds of the first 5 turbines in both columns are hardly affected by the front turbines, so they can be treated as free flows. Under all thermal stability conditions, the wind speed at hub height are close to each other, but the energy generation of each turbine varies so much. This is because thermal stability affects the incident wind profile, and different wind shears result in the difference of energy generation between these turbines. When wind direction is $22.5^{\circ}$, under all thermal stability conditions, the normalized power of each turbine in Column D/E differs about 5\%. Under Stable condition, the normalized power of each turbine in both columns is close; Under Neutral condition, the normalized power of turbines in Column D is a little bit higher than that in Column E; and under Unstable and Very Unstable conditions, the normalized power of turbines in Column $\mathrm{E}$ is a little bit higher than that in Column D. This is because the row spacing of these two columns are different, as well as the upstream water depths and roughness of Column D/E.

When wind direction is $7.5^{\circ}$, under all thermal stability conditions, the normalized power of each turbine in Column D/E differs very much. Under Neutral condition, the normalized power of each turbine in both columns is close. Under Unstable condition, the normalized power of turbines in Column E is $20 \%$ higher than that in Column D; Under Very Unstable condition, the normalized power of turbines in Column $\mathrm{E}$ is $10 \%$ higher than that in Column D. This is because wind shears are different under different stability conditions, and under the joint effect of roughness and thermal stability, finally result in the difference between the energy generation. The wind speeds of turbines in Column D/E are close, it varies little between turbines in the same column, so the output powers of the first 5 turbines in Column D are close. Under all thermal stability conditions, the upstream roughness in Column E could be treated as a constant (because $z_{0}$ is very small), but the output powers differ so much: under Stable and Neutral conditions, $P_{E i} / P_{E 1}<1$; under Unstable and Very Unstable conditions, $P_{E i} / P_{E 1}>1$. For Column D, under all thermal stability conditions, they have a similar law of output power attenuation, and the upstream roughness in Column D could also be regarded as a constant (because $z_{0}$ is very large). So we can draw a conclusion that when roughness is big enough, atmospheric stability has little influence on output power; while sea surface roughness is small enough, atmospheric stability has a dominant influence on output power.

\section{Conclusions}

Wind speed of lower layer varies greatly by the influence of the atmospheric stability in coastal regions. Richardson number combines the effect of the thermodynamic factor and dynamic factor, reflecting more information about turbulent, so it is suitable for the judgment of thermal stability in offshore wind farm. In summer, daily variation of Richardson number changes a little, while it changes a lot in winter, and the value of daily variation is similar in spring and autumn. 
Under stable condition, the power loss of the offshore wind farm is fast, and the output power of wind turbines is affected by different atmospheric stability. When roughness is big enough, atmospheric stability has little influence on output power; while sea surface roughness is small enough, atmospheric stability has a dominant influence on output power of wind turbine.

\section{Acknowledgements}

This work was financially supported by the Jiangsu Province Electric Power Design Institute Foundation (20168007816), International Cooperation of Science and Technology Special Project (2014DFG62530) and Project of Nantong Technology Project (BK2014028).

\section{References}

[1] R.J. BARTHELMIE, S.C. PRYOR, S.T. FRANDSEN et al. Quantifying the Impact of Wind Turbine Wakes on Power Output at Offshore Wind Farms[J]. JOURNAL OF ATMOSPHERIC AND OCEANIC TECHNOLOG, 2009, 27:1302-1317.

[2] Information on http://www.qufair.com/news/2016/07/08/5499.shtml.

[3] Olivier TEXIER, Tristan CLARENC. Integration of atmospheric stability in wind power assessment through CFD modeling[C]. 2012, EWEA, Copenhaven,562-568.

[4] Alfredo Peña, Rogier Floors, Sven-Erik Gryning. The Høvsøre Tall Wind-Profile Experiment: A Description of Wind Profile Observations in the Atmospheric Boundary Layer[J]. BoundaryLayer Meteorol, 2014, 150:69-89.

[5] Alfredo Peña, Pierre-Elouan Réthoré, Ole Rathmann . Modeling large offshore wind farms under different atmospheric stability regimes with the Park wake model[J]. Renewable Energy, 2014,70,164-171.

[6] Andrea Venora. Monin-Obukhov Similarity Theory Applied to Offshore Wind Data Validation of Models to Estimate the Offshore Wind Speed Profile in the North Sea[D]. Delf Univerisity of Technology: 2009.

[7] Blackadar AK. The vertical distribution of wind and turbulent exchange in a neutral atmosphere[J]. Journal of Geophysical Research , 1962; 67(8): 3095-3102.

[8] Lettau HH. Theoretical wind spirals in the boundary layer of a barotropic atmosphere[J]. Beiträge zur Physik der Atmosphäre, 1962; 35: 195-212.

[9] Peña A, Gryning SE, Hasager CB. Comparing mixing- length models of the diabatic wind profile over homogeneous terrain[J]. Theoretical and Applied Climatology, 2010,100: 325-335.

[10] Stull RB. An Introduction to Boundary Layer Meteorology[M]. The Netherlands: Kluwer Academic Publishers, 1988.

[11] Gryning SE, Batchvarova E, Brümmer B, Jørgensen H, Larsen S. On the extension of the wind profile over homogeneous terrain beyond the surface layer[J]. Boundary-Layer Meteorology, 2007,124(2): 251-268.

[12] Nikola Sucevic, Zeljko, Djurisic. Influence of atmospheric stability variation on uncertainties of wind farm production estimation[C]. 2012, EWEA, Copenhaven, 1023-1026.

[13] Sonia Wharton, Julie K Lundquist. Atmospheric stability affects wind turbine power collection[J]. ENVIROMENTAL RESEARCH LETTERS, 2012, 7(1):45-51. 
[14] Mandar Tabib, Adil Rasheed, Trond Kvamsdal. Investigation of the Impact of Wakes and Stratification on the Performance of an Onshore Wind Farm[J]. Energy Procedia, 2015, 80:302-311. 